\title{
THEORY OF TECHNICAL SYSTEMS - LEARNING TOOL FOR ENGINEERING EDUCATION
}

\author{
W. Ernst Eder \\ Royal Military College of Canada (retired) \\ eder-e@kos.net
}

\begin{abstract}
Hubka's theory of technical systems (TTS) describes what is common to all engineering devices, whatever their physical principles. This theory is based on a general transformation system (TrfS), which can be used to show engineering in the contexts of society, economics and historic developments. The TS-life cycle consists of seven major TrfS, each consisting of productspecific TrfS. Each operator of a TrfS is itself a TrfS. The connection to the general economy, and its financial consequences, is shown in the TS-life cycle LC4 with its supply chain, and stages LC6 and LC6A, the operating product with its supply chain and distribution chain. Transformation systems are hierarchical. Each subsystem can be viewed as a TrfS in its own right. Each TrfS is a sub-system to a more complex system. Invention and innovation in TrfS can be shown (historically) to alter the state of society, beneficially and adversely. From this TTS, Hubka derived a systematic methodology as guide to design engineering, novel design and re-design.
\end{abstract}

Keywords: theory of technical systems, transformation process, application to engineering education, design methodology, student orientation.

\section{INTRODUCTION}

Having collaborated with Dr Vladimir Hubka since 1980, and now retired for several years, the author has reached the conclusion that the theory of technical systems has a much wider scope than envisaged by Hubka. As a result, this paper sets out to explore some aspects of this wider scope, and show use of TTS as a pedagogical tool for all branches of engineering education.

Hubka's (non-mathematical) theory of technical systems (TTS) [3,4,20,21], development started around 1965 , describes in summary and detail what is common to all engineering devices, whatever their physical principles. This theory is based on the concept of a general transformation system (TrfS), figure 1. This TrfS includes a transformation process (TrfP), and its five typical operators - human system (HuS), technical system (TS), active and reactive environment (AEnv), information system (IS), and management system (MgtS), all five interacting to delivering effects to a transformation process (TrfP), to transform an operand (Od).

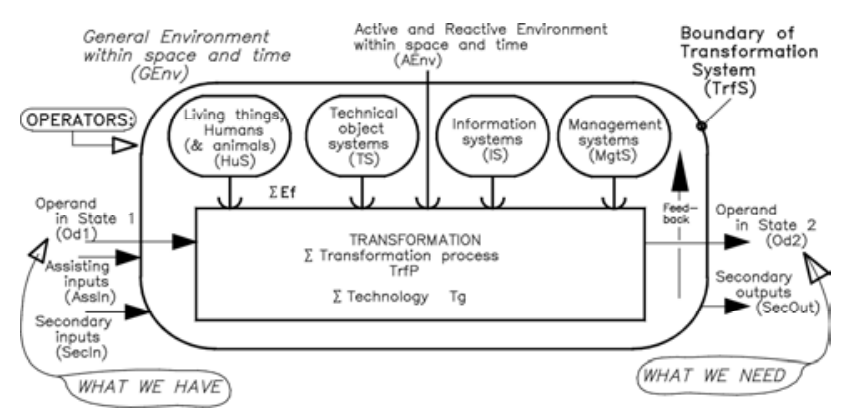

Fig. 1. General Model of a Transformation System $[3,4,20,21]$.

TTS includes a typical TS-life cycle, consisting of seven typical stages, see figure 2 - each life-cycle stage is a transformation system in its own right. In reality, each of these life-cycle TrfS actually consists of several to many TrfS that are product-specific. That technical system that is intended as the tangible product of a manufacturing organization is labelled TS(s) - the subject of interest, the product of that organization - to distinguish it from all other TS. Generally, during life cycle stages LC6 (and LC6A) and LC7 the TS(s) is in the hands of the user, performing (when needed) its intended tasks for that user.

TTS also includes several other propositions that are less interesting for this paper, e.g. properties and structures of transformation processes (TrfP) and technical systems (TS), inputs and outputs of TrfP and its operators, etc.

From this TTS, Hubka derived a fully systematic methodology as voluntary guide to design engineering $[3,4,21]$. This methodology includes recommendations for application to novel design problems, and to re-design, see section 3. It is augmented by case examples (to date 


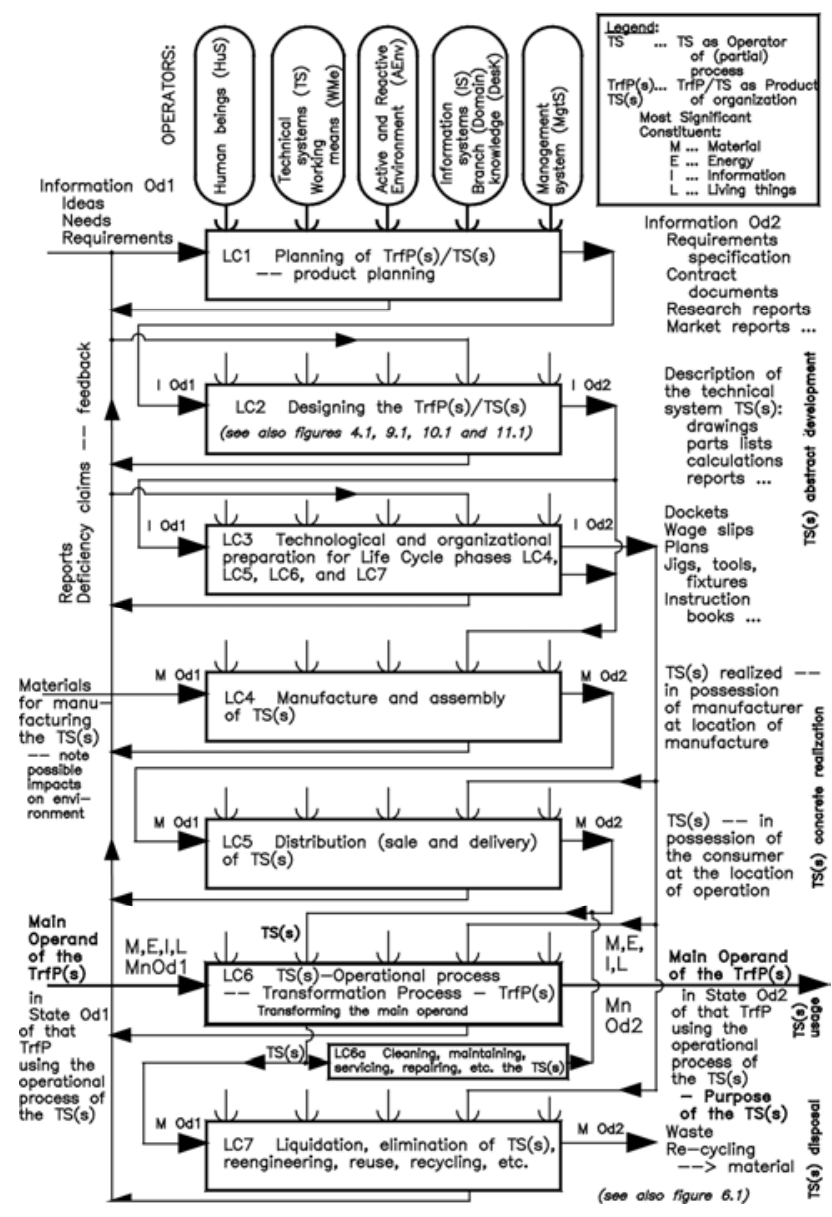

Fig. 2. General Model of the Life Cycle of a Technical System [3,4,20,21].

22), mainly involving simple engineering products, but also more complex ones, novel and re-design problems, and problems which can be sub-divided into a hierarchy of sub-problems e.g. [10,11,13,14,15,16].

\section{SOME EDUCATIONAL ASPECTS}

The model of a transformation system can be used effectively within engineering education to show engineering in the wider contexts of society, economics and historic developments. This also illustrates the range of topics with which an engineer should be familiar, at least in outline.

Each operator of a TrfS is itself a TrfS. This is verified especially by observing the operator 'management system' (MgtS) in the TS-life cycle, see figure 3, right side. Each management system performs its management (transfor-mation) process (TrfP), under the effects of its operators - management human system, management technical systems, active and reactive environment, management information system, and higher-level management system.
Any manufacturing performed by this organization needs to establish its supply chain, to obtain raw materials, part-finished goods (e.g. rolled steel sections), COTS (commercial off-the-shelf products), OEM parts (products for original equipment manufacturers). The connection to the general economy, and its financial consequences, is shown in figure 3 (left side) by considering TS-life cycle LC4, components subject to (national or international) standards, (e.g. rolling contact bearings) etc. - these classes of supplies are not exclusive, e.g. a standard part may also be a COTS or OEM item. Such components are somewhat specialized, they need expertise not generally available, or are obtained cheaper by allowing outside suppliers to design, manufacture and deliver them. Engineering designers need to understand how such individual COTS operate and behave, what limitations they exhibit, how they should be handled (in manufacture, assembly and adjustment), etc. They are generally thought of as simple to complex machine elements, in a revised arrangement as proposed by Weber $[4,5,25]$, including modes of action such as hydraulic, compressible fluid dynamic, electrical, electronic, chemical (e.g. combustion), etc. Although analysis by established theories of the engineering sciences (and costing, etc,) is important, designing these technical artifacts also need synthesis [7]. The outside suppliers of such components may be financially and corporately tied to the subject manufacturer, or be independent and deliver similar products to competing manufacturers.

Life cycle stages LC6 and LC6A show the need to service the operating product. This includes regular maintenance (e.g. oil change), repairs, upgrading additions or modifications to the TS(s) in the hands of the user. These tasks can be performed by the user of the TS(s), by the owner, or by the subject manufacturer in a Product-Service-System relationship - e.g. the subject manufacturer can retain ownership, perform the LC6A tasks, and lease the TS(s) to the user.

TS-life cycle stage LC6 indicates a need to establish a supply chain for inputs to the user's transformation process, and a distribution chain for the user's products each shown in figure 3 as a TrfS left and right of the TSlife cycle. These auxiliary user TrfS are, of course, specific to the product that the user of the TS(s) makes.

Transformation systems are hierarchical. Each subsystem can be viewed as a TrfS in its own right, leading to a repeating use of the same design methodology for sub-systems. Each TrfS is a sub-system to a more complex system. Invention and innovation in TrfS (and especially in TS) can be shown (historically) to alter the state of society, beneficially and adversely, more or less.

The formalization available in TTS [20] has been found useful as insight for reorganizing the product 


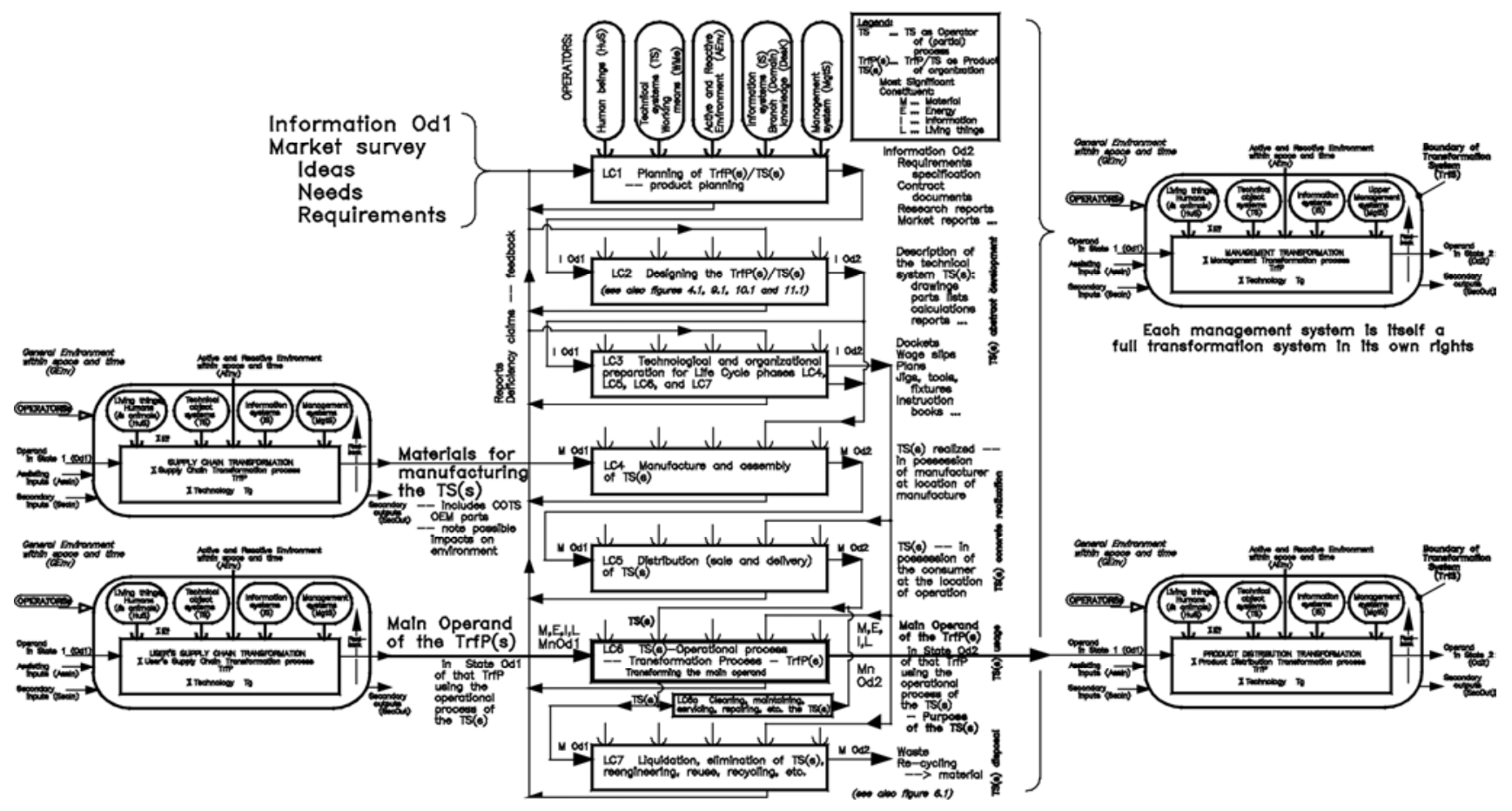

Fig. 3. Extended Model of the Life Cycle of a Technical System

management of a large-scale IT (information technology) organization [23].

All this is general knowledge to many people, although they probably are not aware of this level of formalization. It cannot normally be assumed as general knowledge, it is probably new to engineering students in education, especially in the wider contexts. This exposition also highlights a noteworthy difference between engineering and science: (a) in their aims, (b) their procedures, (c) their required range of knowing and awareness $[3,6,8,12]$.

\section{SYSTEMATIC DESIGN ENGINEERING}

One of the distinguishing features between science and engineering design is that engineers are often involved in designing engineering products (technical systems), LC2, that should operate to the satisfaction of the user, LC6, be economical, be environmentally acceptable, be socially and politically acceptable, etc. (Scientists at times need to design technical systems, but usually not under the time and financial constraints of industry.) In the past, designing for engineering artifacts has been learned by an apprenticeship approach. Little guidance was available for situations when experience and heuristic guidelines led to an impasse. Since the 1960's, various design methods have been proposed, either from experience (e.g. Pahl and Beitz 1977 [22]), or on the basis of experience and a descriptive (non-mathematical) theory (e.g. Hubka $[3,4,20,21]$.
Engineering design can range from routine (e.g. a large power transformer within an organization manufacturing such power transformers to order as their commercial product) to very novel (e.g. the first nuclear reactor for a power station, the first in-cylinder gasoline fuel injector). Innovations in most products usually occur within a smaller sub-system of the product (e.g. the change from carburation to fuel injection for gasoline engines). During such innovations, a critical situation may arise, when the engineering designer lacks guidelines about prior experience and/or the methods or procedures that may help him/her to overcome that situation. This is when a well-founded a systematic methodology can help [9], by providing models, tools and procedures to assist understanding and creativity.

Returning to figure 1, for an existing engineering artifact, each of the elements in the general model of the TrfS can be recognized (determined, analytically, although one or more may have the quantity and/or value of zero - an automatic transmission for a car has no direct effects delivered by the human system).

Synthesis, a component of engineering designing, is not a simple reversal of analysis [7]. Yet a logical progression of steps can be derived from figure 1 to assist novel designing:

(a) establish a design specification, a structured list of requirements for the future system,

(b) establish a time-line for the task,

(c) establish a suitable transformation process (TrfP) and its structure of operations - with alternatives, 
(d) establish what effects (Ef) are needed to drive the technologies of each operation - with alternatives,

(e) establish the TS-internal and cross-boundary functions (and their structure) capable of delivering the effects with alternatives, compare figure 4 ,

(f) establish which TS-organs (and their structure) can realize these functions - with alternatives, usually helped by a morphological matrix,

(g) establish what constructional parts can realize the chosen organ structure - with alternatives,

(h) establish the details of these constructional parts.

Noteworthy is the difference in terminology between analysis and synthesis. In analysis we typically determine and recognize what exists - a convergent mental activity [19]. In synthesis we work towards establishing a proposal that we think is likely to perform the future task - a divergent mental activity. This procedure is illustrated in our case examples, e.g. $[10,11,13,14,15,16]$

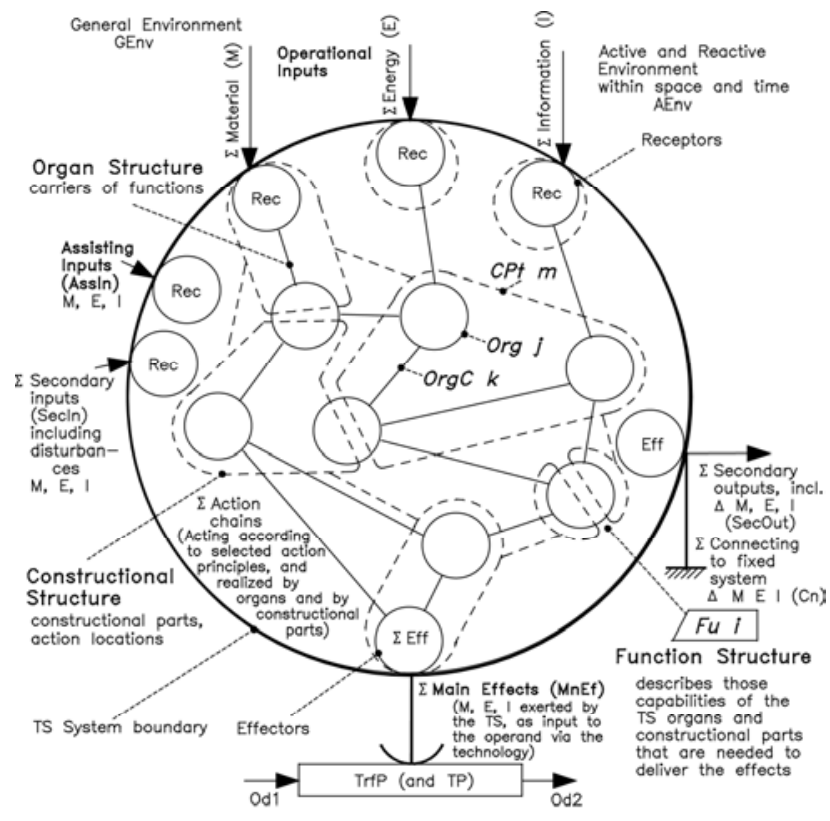

Each technical system exhibits several structures, consisting of different kinds of elements, e.g. functions (Fu i), organs (Org j) and organ connectors ( $\mathrm{OrgC} k$ ), constructional parts ( $\mathrm{CP} \mathrm{m}$ ) and their relationships.

Fig. 4. Structures of Technical Systems $[3,4,20,21]$.

Redesign also starts with (a) establish a design specification, a structured list of requirements for the future system, as above, including the desired alterations. It then continues: $(\mathrm{Rg})$ analyze the organs and organ groups (re-engineering, therefore the designation $\mathrm{Rg}$ ) from the constructional structure, $(\mathrm{Re})$ formulate the TSfunctions and their structure, (e) change the TS-function structure according to the new requirements, and continue with steps (f), (g), and (h) as for novel design.

This sequence cannot be performed in this apparently linear fashion - both iterative working, and recursion (sub-dividing the problem and recombining) are essential operations. In each step of the design process, additional activities need to be performed: orthogonal to the design process is a cycle of problem solving: (1) define the problem, (2) search for solutions, (3) evaluate and decide, and (4) communicate, supported by (5) prepare information, (6) check, verify, and (7) represent $[3,4,20,21]$, augmented by recent insights by Weber [24].

\section{COMPARISON HUBKA - PAHL/BEITZ}

The methodology developed by Pahl and Beitz [22] (and largely adopted by VDI - Verein deutscher Ingenieure, Association of German Engineers) was derived directly (as a design methodology) and pragmatically from the engineering design experience of the authors, and is firmly based in Mechanical Engineering. This engineering design methodology is good in the later embodiment detailed stages, with ample advice for many aspects of layout and detail. The descriptive (non-mathematical) theory underpinning this Pahl-Beitz design methodology is not spelled out, and tends to be somewhat rudimentary, with little attempt at completeness and comprehensive applicability for all engineering products - technical systems. The methodology needs enhancement in the early stages of conceptualizing and embodiment-in-principle, especially where a novel product or a radical innovation is desired.

The highest abstraction recognized by Pahl-Beitz is the 'function structure', a structure consisting of inter-related functions - it combines steps (c), (d) and (e) from the scheme in section 3. A 'function' is defined as the capability for doing something (simple to complex), and is formulated in a verb or verb phrase combined with a noun or noun phrase. There is no differentiation between a TrfP and a TS-internal or cross-boundary function, as in Hubka $[3,4,20,21]$. A main purpose function needs to be recognized, which is subjected to 'function decomposition' to recognize the sub-functions and (eventually) elemental functions which cannot (usefully) be further decomposed, see figure 5. Few methodical tools and guidelines are offered by Pahl and Beitz to help with decomposition.

The overall design process is illustrated as in figure 6 . It is noteworthy that sub-processes such as 'evaluating' and 'deciding' are only implied, and that 'searching for solutions' is specifically mentioned as step 3 , but only in the context of 'principle solutions' - Hubka [3,4,21] includes these activities in the problem solving cycle.

The transition from the function structure towards the components (constructional parts) is achieved by applying 'physics' (covering all modes of action) suppressing the importance of an organ structure. 


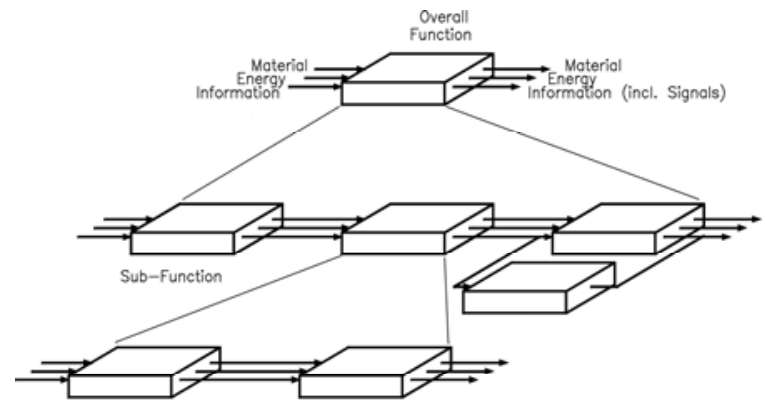

An example of this type of function structure is shown in figure 3 [Pohl and Beitz 1996] Adapted from Springerimages 2012 (www.springerimages.com/Images/Engineering)

Fig. 5. Function Decomposition according to Pahl and Beitz [22].

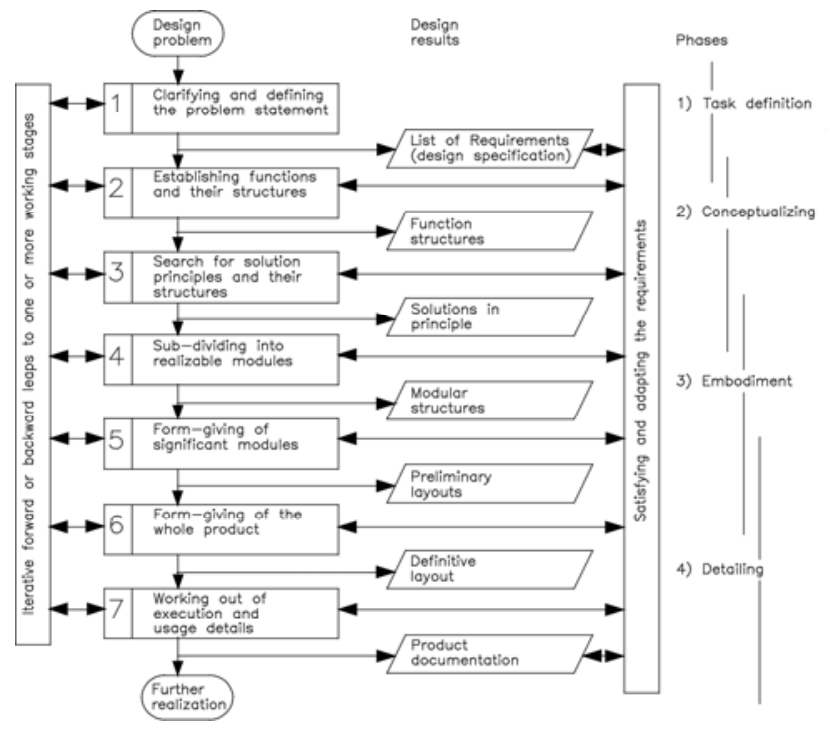

Fig. 6. Design Methodology according to VDI 2221

$[1,2]$.

In contrast to Hubka [21], Pahl and Beitz [22] do not cover: (1) a formalized life cycle, (2) formalized lists of classes of properties of TS and TrfP, (3) formalized list of classes of requirements, (4) a problem solving cycle, (5) case examples of the design approach to designing technical systems, (6) consideration of other design methods, and several other contributing items. On the positive side, the vast array of advice given by Pahl and Beitz [22] about the constructional structure makes this a very valuable work for mechanical engineering designers.

\section{CLOSURE}

The theory of technical systems is shown to be a valuable tool for expanding the horizons of engineering students, and bringing engineering into societal context. In addition, it leads to a systematic design methodology that is suitable for novice engineering designers, provides good insights for their future activities, and assists them whenever they tend to exceed their (currently) highest level of competence.

\section{References}

[1] - VDI Richtlinie 2221:1985 Methodik zum Entwickeln und Konstruieren technischer Systeme und Produkte (Methodology for Developing and Designing Technical Systems and Products), Düsseldorf: VDI, 1985

[2] - VDI Guideline 2221:1987 Systematic Approach to the Design of Technical Systems and Products, Düsseldorf: VDI (edited by K.M. Wallace), 1987

[3] Eder, W.E. (1996) 'Engineering Design - Mediating a Transition from Science to Engineering', 1996 Canadian Conference on Engineering Education - C2E2, Kingston, Ont, 16-18 June 1996, p. 253-258

[4] Eder, W.E. (2004) 'Machine Elements - Integration Of Some Proposals', Proc. AEDS 2004 Workshop, The Design Society - AEDS-SIG, 11-12 Nov 2004, Pilsen, Czech Republic, on CD-ROM, http://www.kks.zcu.cz/aeds

[5] Eder, W.E. (2005) 'Machine Elements - Revision and Outlook for Design Education', in Proc. Second CDEN International Conference, University of Calgary, Alberta, 18-19 July 2005 at Kananaskis Resort, paper 10006 on CDROM

[6] Eder, W.E. (2007) 'Design Engineering - Not Just Applied Science', in Proc. CDEN/CCEE - Canadian Design Engineering Network and Canadian Conference on Engineering Education, 22-24 July 2007, U. of Manitoba, Winnipeg, Manitoba, on CD-ROM

[7] Eder, W.E. (2008) 'Aspects of Analysis and Synthesis in Design Engineering', in Proc. CDEN 08, Halifax, N.S., 2729 July 2008, on CD-ROM

[8] Eder, W.E., 'Engineering Design - Art, Science and Relationships', Design Studies, Vol. 16, 1995, p. 117-127.

[9] Eder, W.E. (2009) 'Why Systematic Design Engineering?' in Proc. $6^{\text {th }}$ Symposium on International Design and Design Education, August 30 - September 2, 2009, San Diego, California, USA, New York: ASME, paper number DETC2009-86067

[10] Eder, W.E. (2009) 'Case Study in Systematic Design Engineering - Smoke Gas Dust Precipitation', paper ASME DETC2009-86069 in Proceedings of the $6^{\text {th }}$ Symposium on International Design and Design Education, DEC 6, August 30 - September 2, San Diego, California, USA

[11] Eder, W.E. (2010) 'Case Study in Systematic Design Engineering - Trapeze Demonstration Rig', paper ASME DETC2010-28065 in Proc. $7^{\text {th }}$ Symposium on 
International Design and Design Education, DEC 7, 1518 August, Montreal, Quebec, Canada

[12] Eder, W.E. (2011) 'Theory of Technical Systems Relationships to Engineering Sciences', paper 3 in Proc. CEEA 2011 Conference, 6-8 June 2011, Memorial University, St. Johns, Newfoundland

[13] Eder, W.E. (2012) 'Case Example in Systematic Design Engineering - Leeboard Mounting', for Proc. International Design Conference - DESIGN 2012, Dubrovnik - Croatia, May 21-24, 2012

[14] Eder, W.E. (2012) 'Case Example in Systematic Design Engineering - Propeller Shaft Bearing Arrangement', for Proc. International Design Conference - DESIGN 2012, Dubrovnik - Croatia, May 21-24, 2012

[15] Eder, W.E. (2012) 'Case Study in Systematic Design Engineering - Wind Tunnel Balance Model Support', paper number 9 in Proc. Canadian Engineering Education Association CEEA 2012 Conference, 17-20 June 2012, University of Manitoba, Winnipeg, MB

[16] Eder, W.E. and Heffernan, P.J. (2009) 'A Case Study in Systematic and Methodical Design Engineering', in Proc. CDEN/C2C2 Conference 2009, 27-29 July, McMaster University, Hamilton, ON

[17] Eder, W.E. and Hosnedl, S (2008) Design Engineering: A Manual for Enhanced Creativity, Boca Raton: CRC-Press

[18] Eder, W.E. and Hosnedl, S. (2010) Introduction to Design Engineering - Systematic Creativity and Management, Leiden (The Netherlands): CRC Press / Balkema

[19] Guilford, J.P. (1970) 'Traits of Creativity', in Anderson, H.H. (ed.), Creativity and its Cultivation, New York:
Harper \& Row, 1959, p. 142-161 (Reprinted in Vernon, P.E. (ed.), Creativity, Harmondsworth: Penguin, p. 167-188)

[20] Hubka, V., and Eder, W.E. (1988) Theory of Technical Systems: A Total Concept Theory for Engineering Design, New York: Springer-Verlag

[21] Hubka, V. and Eder, W.E. (1996) Design Science: Introduction to the Needs, Scope and Organization of Engineering Design Knowledge, London: Springer-Verlag, http://deseng.ryerson.ca/DesignScience/

[22] Pahl, G., Beitz, W., Feldhusen, J. and Grote, H-K. (2007) Engineering Design (3 edn.), London: Springer-Verlag (1 edn. 1984) (Edited and translated by K. Wallace and L. Blessing), translated from 2003-5th edn. of Pahl, G. and Beitz, W., Feldhusen, J. and Grote, H-K. (2007) Konstruktionslehre, Methoden und Anwendungen, (7 edn.) Berlin/Heidelberg: Springer-Verlag (1 edn. 1977)

[23] Sillitto, H.G. (2013) "'Simple Simon met a System" bridging the gap to the rest of the organisation', in Proc. 1999 International Symposium, International Council on Systems Engineering, Brighton, England, 6-11 June 1999, p. 993-1000

[24] Weber, C. (2008) 'How to Derive Application-Specific Design Methodologies', in Proc. 10th International Design Conference - DESIGN 2008 Dubrovnik, FMENA, Zagreb, p. $69-80$

[25] Weber, C. and Vajna, S. (1997) 'A New Approach to Design Elements (Machine Elements)'. In Riitahuhta, A. (ed.) WDK 25 - Proc. ICED 97 Tampere, Tampere University, Vol. 3, 1997, p. 685-690 